\section{Short- and long-term results of chordal reconstruction using artificial suture material (polytetrafluoroethylene and polypropylene) in the dog}

Isamu Kanemoto, ${ }^{1}$ Tomonari Masumoto, ${ }^{1}$ Kiminari Ohara, ${ }^{1}$ Yusuke Kimura, ${ }^{2}$ Noboru Machida2

1Chayagasaka Animal Hospital, Nagoya, Aichi; 2Laboratory of Veterinary Clinical Oncology, Tokyo University of Agriculture and Technology, Fuchu, Tokyo, Japan

\begin{abstract}
No previous reports have compared the suitability of expanded polytetrafluoroethylene (ePTFE) and polypropylene as artificial suture materials for chordal reconstruction in mitral valve plasty (MVP) in the dog. Twelve normal dogs were subjected to MVP using surfaceinduced deep hypothermia. In the short-term group (1.5-4 months after surgery), all ePTFE sutures were covered by a tissue sheath including the paired suture arms, which gave the appearance of native chordae from 2 months after surgery. In contrast, all polypropylene sutures were not covered by tissue, and appeared the same as the paired polypropylene suture arms at the operation. In the long-term group (12 months after surgery), all ePTFE sutures were covered by a tissue sheath, which
\end{abstract}

appeared the same as that in the short-term group, and had flexibility without increased thickness with time. In contrast, although the polypropylene suture was covered completely by a tissue sheath in $1 \mathrm{dog}$, all the other polypropylene sutures were exposed except for both ends of the suture. ePTFE may be superior to polypropylene as an artificial suture material for chordal reconstruction in MVP.

\section{Introduction}

Myxomatous degeneration of the mitral valve results in elongation or rupture of the chordae tendineae and is the most common cause of mitral regurgitation (MR) in the dog. ${ }^{1}$ Two surgical procedures have been described in the treatment of MR in humans ${ }^{2}$ and dogs, ${ }^{3-}$ ${ }^{9}$ mitral valve replacement (MVR) and mitral valve plasty (MVP). MVP is preferred to MVR as the first choice in surgical treatment of MR in humans, ${ }^{10}$ because postoperative anticoagulant therapy is not required. Optimal anticoagulant effects are hard to control in dogs; 5 therefore, this is a factor in favor of the use of MVP rather than MVR in this species. Artificial material is needed for chordal reconstruction in most MR cases, ${ }^{11-13}$ and expanded polytetrafluoroethylene (ePTFE) has been used with good results in clinical MR cases in humans ${ }^{14-}$ 16 and dogs. 7,9 There are detailed experimental reports on the use of ePTFE sutures as artificial chordae in sheep. ${ }^{13}$ However, similar study in dogs is limited and small scale. ${ }^{14}$ In addition, there is no report comparing ePTFE and polypropylene sutures as artificial chordae for chordal reconstruction in the dog.
Correspondence: Isamu Kanemoto, Chayagasaka Animal Hospital, 1-1-5 Shinnishi, Chikusa-ku, Nagoya, Aichi 464-0003, Japan.

Tel.: +81-52-773-1866 - Fax: +81-52-773-7488.

E-mail: kanemoto@ta2.so-net.ne.jp

Acknowledgments: The authors are grateful to Drs. Junzou Kitoh and Mituya Murase, Nagoya University, School of Medicine, for their assistance with experiments. We would like to thank Editage (www.editage.jp) for English language editing.

Key words: chordal reconstruction, artificial chorda, polypropylene (Prolene), polytetrafluoroethylene (ePTFE), dog.

Contributions: the authors contributed equally.

Conflict of interest: the authors declare no potential conflicts of interest.

Conference presentation: this paper was presented in part at the 20 $0^{\text {th }}$ Congress of the World Small Animal Veterinary Association (WSAVA), p 654, Yokohama, Japan. (Kanemoto I, Masumoto T, Ohara K, et al. (1995): Canine mitral valvuloplasty by chordal replacement using artificial suture).

Received for publication: 8 July 2016 .

Accepted for publication: 23 August 2016.

This work is licensed under a Creative Commons Attribution NonCommercial 4.0 License (CC BYNC 4.0).

CC Copyright I. Kanemoto et al., 2017

Licensee PAGEPress srl, Italy

Veterinary Science Development 2017; 7:6683

doi:10.4081/vsd.2017.6683

Table 1. Study subject characteristics and experimental results of MVP using artificial suture material (ePTFE and polypropylene).

\begin{tabular}{|c|c|c|c|c|c|c|c|}
\hline No. & Breed & Sex & Body weight (kg) & Al-2 & A2-3 & Postop SM & Postop days \\
\hline 1 & Mixed & $\mathrm{F}$ & 6.7 & ePTFE & Prolene & - & 45 \\
\hline 2 & Beagle & M & 10.4 & Prolene & ePTFE & - & 50 \\
\hline 3 & Beagle & $\mathrm{F}$ & 5.9 & ePTFE & Prolene & - & 61 \\
\hline 4 & Beagle & M & 7.4 & Prolene & ePTFE & - & 62 \\
\hline 5 & Beagle & $\mathrm{F}$ & 6.9 & ePTFE & Prolene & - & 89 \\
\hline 6 & Mixed & $\mathrm{F}$ & 8.4 & Prolene & ePTFE & $1 / 6$ & 92 \\
\hline 7 & Mixed & M & 11 & Prolene & ePTFE & $1 / 6$ & 115 \\
\hline 8 & Mixed & $\mathrm{F}$ & 7.3 & ePTFE & Prolene & - & 119 \\
\hline 9 & Beagle & M & 8.5 & Prolene & ePTFE & - & 355 \\
\hline 10 & Beagle & $\mathrm{F}$ & 7.6 & ePTFE & Prolene & - & 364 \\
\hline 11 & Mixed & M & 12.5 & ePTFE & Prolene & - & 365 \\
\hline 12 & Mixed & $\mathrm{F}$ & 7.8 & ePTFE & Prolene & - & 375 \\
\hline
\end{tabular}

ePTFE, expanded polytetrafluoroethylene; Prolene, polypropylene; Postop SM, postoperative systolic murmur; A1-2, reconstructed $\mathrm{A}_{1-2}$ strut chorda of the anterior leaflet; A2-3, reconstructed $\mathrm{A}_{2-3}$ strut chorda of the anterior leaflet. 
This study aimed to investigate the suitability of ePTFE and polypropylene as artificial material for chordal reconstruction in MVP in the dog.

\section{Materials and Methods}

This study was carried out according to the animal care guidelines in place at the time at the School of Medicine, Nagoya University, from 1994 to 1995 . Twelve dogs (6 mixed breeds and 6 beagles) were divided into 2 groups: the short-term (1.5-4 months; 8 dogs) and the long-term (12 months; 4 dogs) groups. The mean body weight was $8.4 \mathrm{~kg}$ (range: 5.9 $12.5 \mathrm{~kg}$ ) (Table 1).

An open-heart method with surface-induced deep $\left(20^{\circ} \mathrm{C}\right)$ hypothermia under ether anesthesia was employed. ${ }^{6}$ The surgical approach consisted of a left 5th intercostal thoracotomy and left atriotomy in the right recumbent position. Two strut chordae of the anterior leaflet $\left(\mathrm{A}_{1-2}, \mathrm{~A}_{2-3}\right)$ were resected (Figure $\left.1 \mathrm{~A}\right)$. The artificial sutures used in the study included ePTFE (Gore-Tex $^{\circledR}$ CV-5; Gore-Tex; WL Gore \& Associates, Inc., Flagstaff, AZ, USA) and polypropylene (Prolene ${ }^{\circledR} 4-0$; Prolene; Ethicon, Somerville, NJ, USA) with 2 needles, one at each end. Both types of sutures consist of synthetic, nonabsorbable monofilament material; however, the surface of the former is microporous while that of the latter is smooth. The $A_{1-}$. 2 and $\mathrm{A}_{2-3}$ chordae were replaced with either an ePTFE or a polypropylene suture; if the $A_{1-2}$ chorda was replaced with an ePTFE suture, the $\mathrm{A}_{2-3}$ chorda was replaced with a polypropylene suture, and vice versa (Table 1).

Chordal reconstruction was carried out as follows. A suture with a pair of needles was secured at the site of the resected chorda in each papillary muscle by suturing in a figureof- 8 pattern. Next, each needle was passed in a scroll-like pattern from the ventricular to atrial side at either side of the remnant of the resected chorda in the anterior leaflet (Figure 1B). The length of the artificial suture was then adjusted to that of the neighboring chorda, and the suture ends were ligated at the atrial side.

Each dog was euthanized with pentobarbital anesthesia at a predetermined postoperative stage (45-375 days). After gross examination, the heart specimens were fixed in Bouin's solution for light microscopy and in osmic acid for scanning electron microscopy.

\section{Results}

All dogs survived and had no clinical signs of thromboembolism or heart failure after the surgery. Two dogs exhibited postoperative
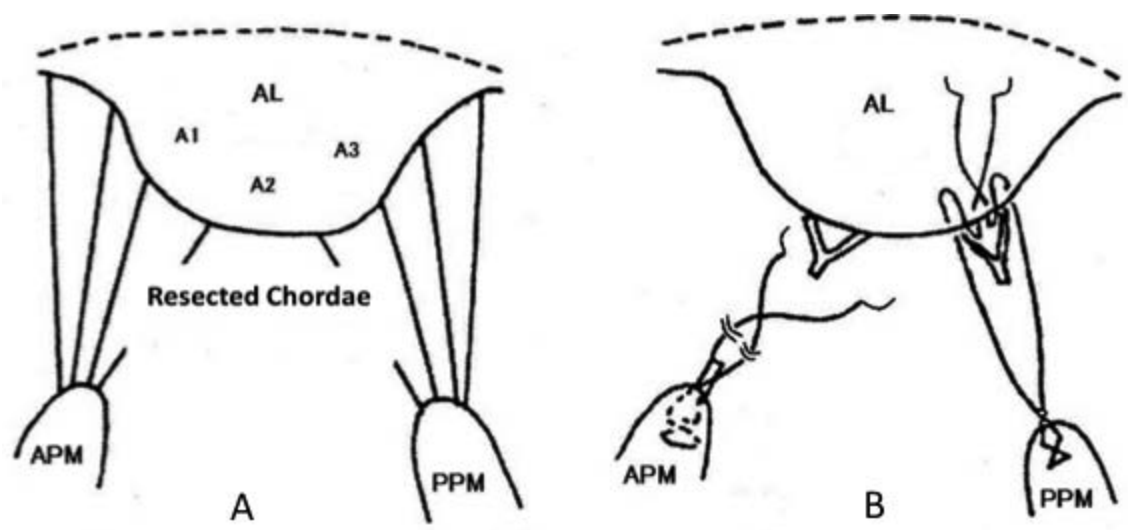

Figure 1. Surgical diagram of resected chordae (A) and the chordal reconstruction method (B). Two strut chordae $\left(A_{1-2}, A_{2-3}\right)$ of the anterior leaflet were resected and reconstructed using 2 types of artificial suture material. The suture was secured at the site of attachment of the resected chorda to the papillary muscle with a figure-of- 8 suture pattern. Each needle of the suture arms was passed in a scroll-like pattern through either side of the anterior leaflet at the site of the resected chorda. The length of the artificial suture was adjusted according to that of the neighboring chorda, and the suture was ligated at the atrial side. AL, anterior leaflet; APM, anterior papillary muscle; PPM, posterior papillary muscle.

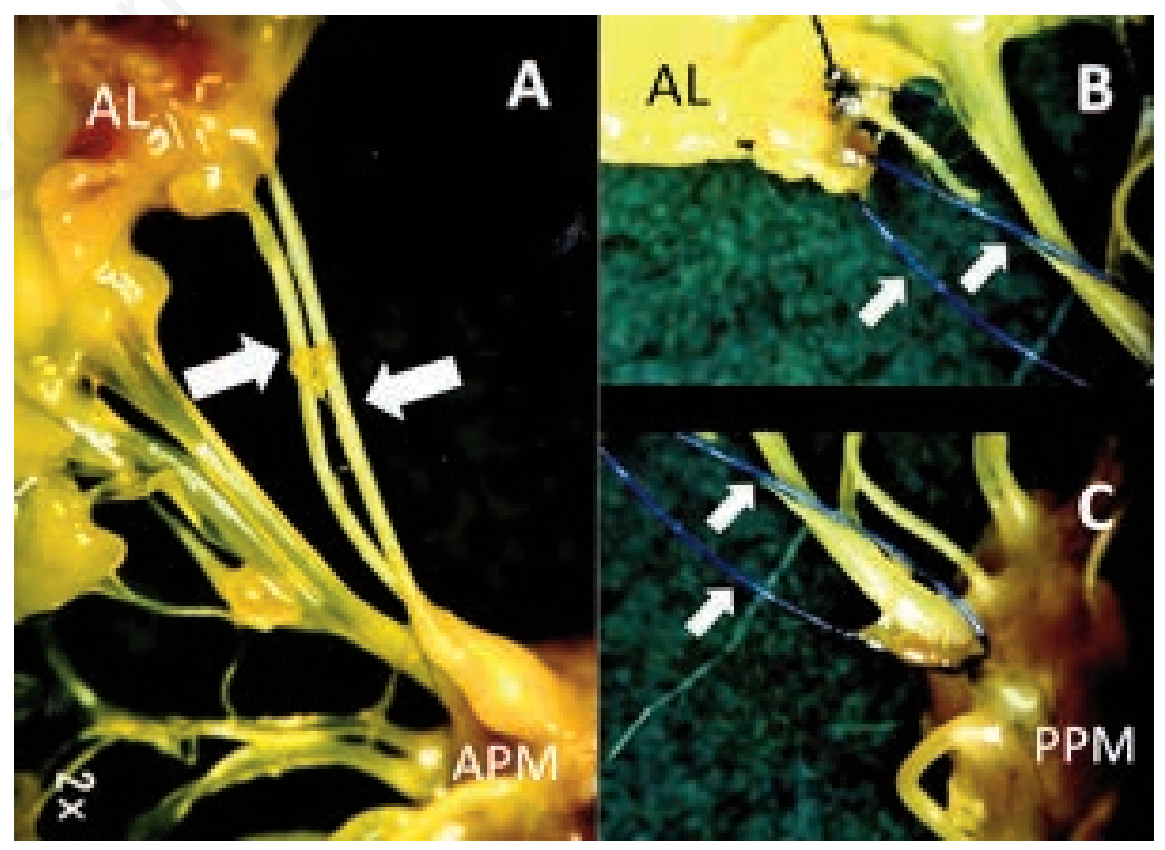

Figure 2. Macroscopic photograph of No. 1 (45 days after the operation). The paired ePTFE suture arms (arrows) are not covered by a tissue sheath except at the papillary muscle and anterior leaflet sides (A). In contrast, the paired polypropylene suture arms (arrows) are not covered by tissue at both the anterior leaflet side (B) and papillary muscle side (C). 
Levine 1/6 systolic murmur due to inappropriate length of the artificial suture (Table 1).

Results in the short-term group were as follows. At 45 and 50 days postoperatively, the surface of each ePTFE suture was covered by a thin layer of delicate connective tissue, and retained the appearance of a paired ePTFE suture except at the papillary muscle and anterior leaflet sides (Figure 2). However, 2 months or more after the operation, the paired ePTFE suture was surrounded by a connective tissue sheath and appeared like a native chorda. In contrast, all polypropylene sutures were devoid of any tissue throughout the whole length and gave the appearance of a paired polypropylene suture, similar to the appearance at the time of the operation (Figure 3 ).

Results in the long-term group were as follows. All ePTFE sutures were covered by a connective tissue sheath, similar to the short-term group, and had not thickened with time (Figure 4). On the other hand, all polypropylene sutures were exposed with no connective tissue covering except at either end of the suture; there was however an exception in 1 $\operatorname{dog}$ (No. 10), in which the paired polypropylene suture arms were surrounded by a connective tissue sheath (Figure 5). On histological examination, the connective tissue sheath consisted of a layer of dense collagenous tissue with an endothelial lining. Various numbers of fibroblastic cells were interspersed with bundles of collagenous fibers. The collagenous fibrous tissue extended into the numerous microscopic pores of the ePTFE suture to varying degrees, thereby creating a close connection between the artificial chorda and the surrounding fibrous tissue (Figure 6; No. 4). These histological findings were confirmed by scanning electron microscopy (Figure 7A). However, the polypropylene suture in No. 10 had no connection with the surrounding connective tissue and seemed to slide within the sheath (Figure 7B).

\section{Discussion}

Artificial material used for reconstruction of the chordae tendineae of the mitral valve requires the following properties: minimal foreign-body reaction and resultant thrombosis, preservation of flexibility, and good durability.

There are many experimental reports about the suitability of various artificial materials for reconstruction of the chordae tendineae of the mitral valve. Early reports ${ }^{11}$ on silk, Teflon, and Dacron warn about the danger of thrombosis and degeneration over time. Relatively recent reports 11,12 on autologous and xenograft pericardium suggest that gradual loss of flexibility caused by partial calcification and fibrous thickening of the pericardium graft resulted in

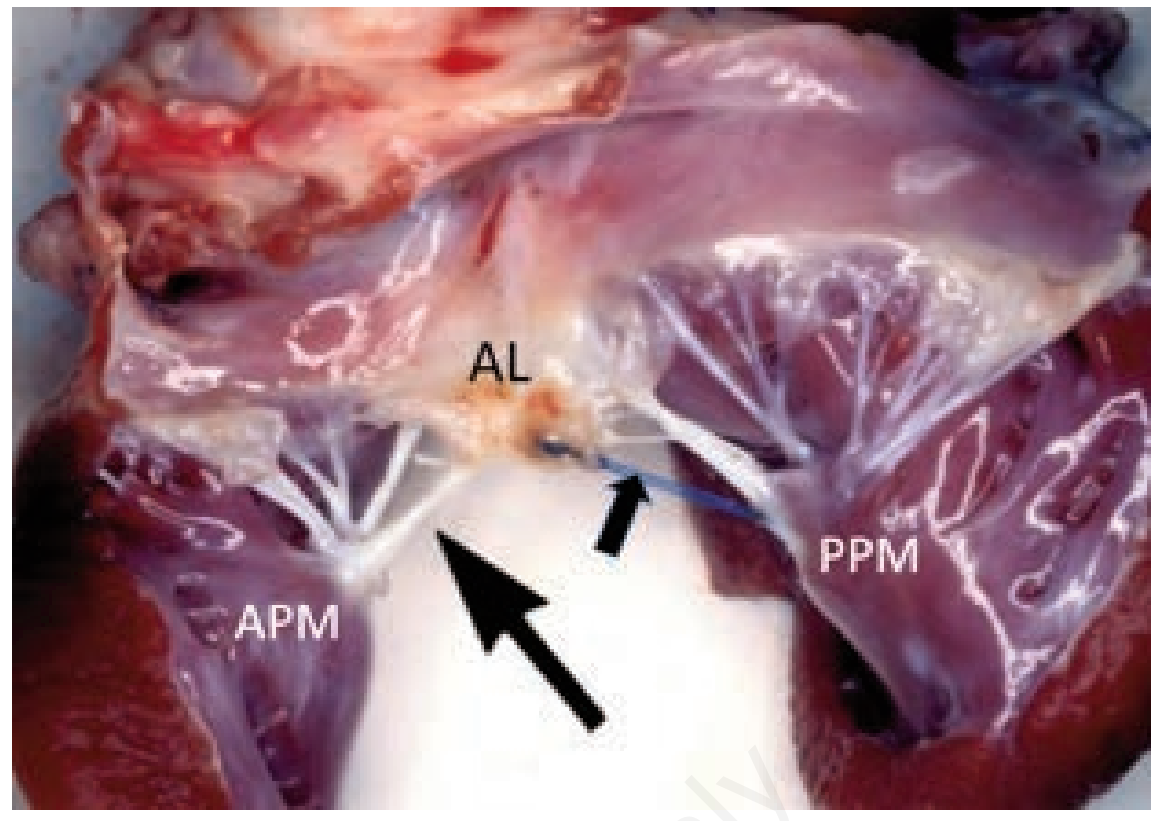

Figure 3. Macroscopic photograph of No. 3 (61 days after the operation). The paired ePTFE suture arms are covered together by the tissue sheath and form a single chorda, giving the appearance of a native chorda in this dog (large arrow). In contrast, the paired polypropylene suture arms are not covered by tissue (small arrow).

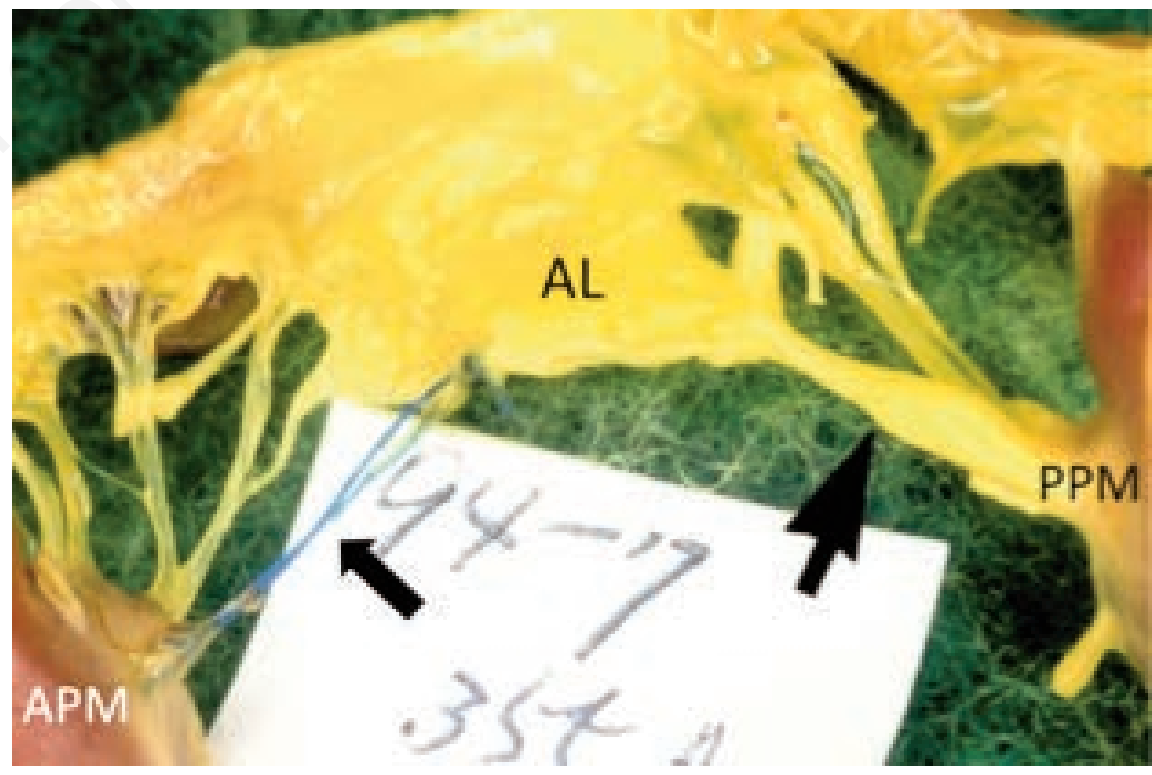

Figure 4. Macroscopic photograph of No. 9 (355 days after the operation). Although the sheath covering the paired ePTFE suture arms has not changed (large arrow), the paired polypropylene suture arms on the papillary muscle side are partially covered by a tissue sheath (small arrow). 
maintenance of competence for only up to 3 years. A recent study investigating the use of ePTFE suture in sheep 13,14 and dogs 14 reports good results with this artificial material as mitral valve chordae tendineae. A large-scale study 13 in sheep has revealed that the ePTFE sutures were completely covered with endocardial tissue from the papillary muscle from 3 months after the operation. A small-scale study $^{14}$ of the use of ePTFE suture in 4 dogs presents good results 13 months after the operation. Most recently, a long-term clinical report shows good results with ePTFE sutures in 2 small dogs, which survived for approximately 9 years after the MVP operation. 17

In the current study, each ePTFE suture was covered with endocardial tissue from both the papillary muscle and anterior leaflet sides from 1.5 months after the operation, and each ePTFE suture was completely covered by a tissue sheath and appeared like a native chorda from 2 months after the operation in the shortterm group. In the long-term group, the ePTFE suture showed no changes in thickness or flexibility 12 months after the operation and appeared like a native chorda, as reported in sheep. ${ }^{13}$ Interestingly, in humans who underwent re-operation for recurrence of MR at 9 months after the clinical operation, the ePTFE suture material was only covered by fibrous tissue where it was in contact with the leaflets and papillary muscles. 15 Coverage of ePTFE suture arms with a tissue sheath appears to occur earlier in dogs than in sheep and humans.

In contrast, the paired polypropylene suture arms were not covered by tissue in the shortterm group and, except in $1 \mathrm{dog}$, only partially covered with endocardial tissue from both the papillary muscle and anterior leaflet sides in the long-term group.

On microscopic and ultramicroscopic examination, the ePTFE suture arms were connected with the surrounding tissue sheath by fibrous bridges in both dog groups, and calcification was not detected in the new chordae; these findings were similar to those found in sheep. The polypropylene suture did not, however, show any connection with the tissue sheath and appeared to slide within the tissue sheath, even in the single dog with a tissuecovered polypropylene suture.

A limitation of the present study is that the number of study subjects was small, particularly for the first 2 months postoperatively during which both suture types essentially retained their appearance at the time of the surgery. Further large-scale studies are warranted to fully investigate postsurgical changes after chordal reconstruction in dogs.

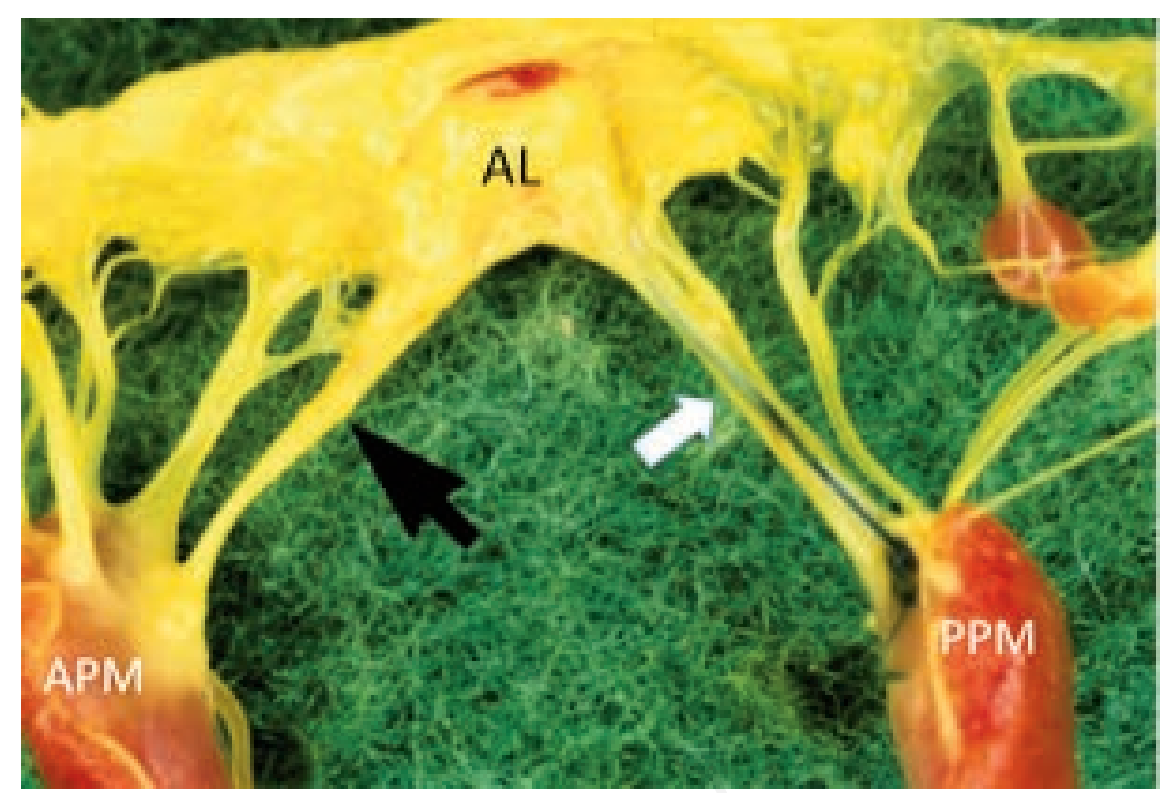

Figure 5. Macroscopic photograph of No. 10 (364 days after the operation). The paired ePTFE suture arms are covered with a sheath, similar to that in the short-term results, giving the same appearance as the native chorda. The artificial chorda has not increased in thickness with time (large black arrow). In this dog, the paired polypropylene suture arms have eventually been covered by a tissue sheath (small white arrow).

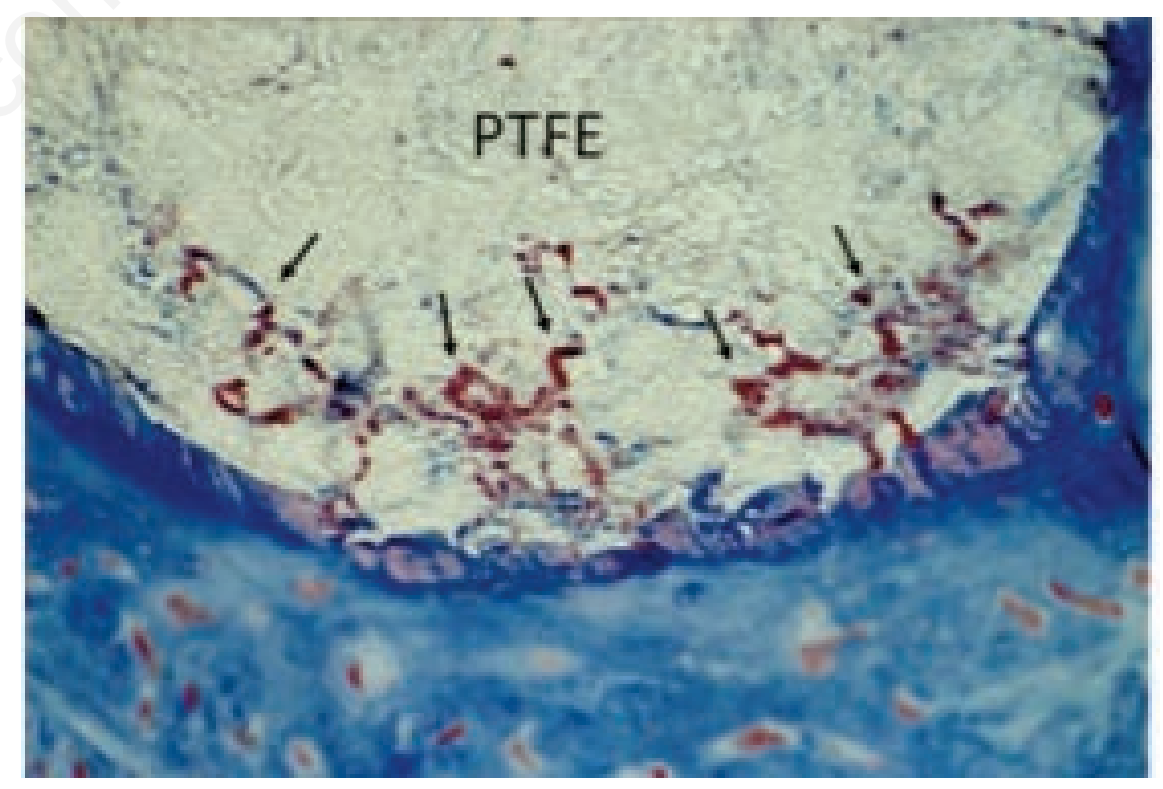

Figure 6. Microscopic photograph of an ePTFE suture 2 months after the operation (No. 4) (Azan-stain, $\times 100)$. The collagen tissue (small arrows) intrudes into the many microscopic pores in the ePTFE suture (PTFE), and the ePTFE suture is closely connected with the surrounding tissue by the fibrous bridges. 

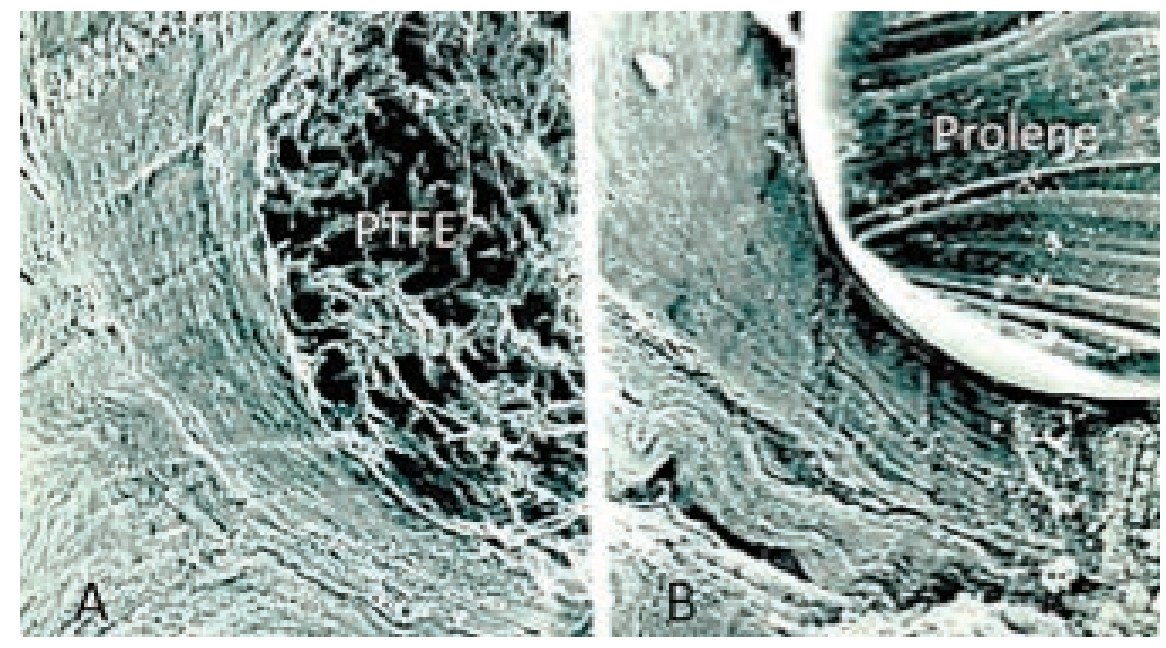

Figure 7. Scanning electron microscope photograph of an ePTFE suture 375 days (left; No. 12) and a polypropylene suture 364 days (right; No. 10) after the operation. The ePTFE suture (PTFE) is closely connected with the surrounding tissue sheath by fibrous bridges (A), although the polypropylene (Prolene) suture is not (B).

\section{Conclusions}

In the comparison of ePTFE and polypropylene for use in MVP in the dog, there does not appear to be any difference in durability or flexibility between the 2 suture materials. However, from the viewpoint of thrombus risk, ePTFE may be superior to polypropylene because the former is completely covered with an endocardial tissue sheath from 2 months after surgery.

\section{References}

1. Kittleson MD, Kienle RD. Myxomatous atrioventricular valvular degeneration. In: Kittleson MD, Kienle RD, eds. Small animal cardiovascular medicine. Kimberton: Mosby; 1998. pp. 297-318.

2. Kirklin JW, Barratt-Boyes BG. Special situ- ation and controversies. Mitral repair or replacement. In: Kirklin JW, Barratt-Boyes BG, editors. Cardiac surgery. 1st ed. New York: Churchill Livingstone; 1988. pp. 36465.

3. Eyster GE, Weber W, Chi S, et al. Mitral valve prosthesis for correction of mitral regurgitation in a dog. J Am Vet Med Assoc 1976;168:1115-8.

4. Orton EC, Hackett TB, Mama K, Boon JA. Technique and outcome of mitral valve replacement in dogs. J Am Vet Med Assoc 2005;226:1508-11.

5. Taguchi D, Kanemoto I, Yokoyama S, et al. Mitral valve replacement with a mechanical valve for severe mitral regurgitation in a small dog. Case Report Vet Med 2014;2014:892625.

6. Kanemoto I, Shibata S, Noguchi H, et al. Successful mitral valvuloplasty for mitral regurgitation in a dog. Jpn Vet Sci 1990;52:411-4.

7. Kanemoto I, Suzuki H, Taguchi D, et al.
Successful surgical repair for severe mitral regurgitation in five small-breed dogs. Vet Surg 2004;33:E12.

8. Griffiths LG, Orton EC, Boon JA. Evaluation of techniques and outcome of mitral valve repair in dogs. J Am Vet Med Assoc 2004;224:1941-5.

9. Uechi M, Mizukoshi T, Mizuno T, et al. Mitral valve repair under cardiopulmonary bypass in small-breed dogs: 48 cases (2006-2009). J Am Vet Med Assoc 2012;10:1194-201.

10. Carpentier A. Cardiac valve surgery: the French correction. J Thorac Cardiovasc Surg 1983;86:323-37.

11. Rittenhouse EA, Davis CC, Wood SJ, Sauvage LR. Replacement of ruptured chordae tendineae of the mitral valve with autologous pericardial chordae. J Thorac Cardiovasc Surg 1978;75:870-6.

12. Frater RWM, Gabbay S, Shore D, et al. Reproducible replacement of ruptured mitral valve chordae. Ann Thorac Surg 1983;35:14-28.

13. Revuelta JM, Garcia-Rinaldi R, Gaite L, et al. Generation of chordae tendineae with polytetrafluoroethylene stents. Results of mitral valve chordal replacement in sheep. J Thorac Cardiovasc Surg 1989;97:98-103.

14. Zussa C, Frater RWM, Polesel E, et al. Artificial mitral valve chordae: experimental and clinical experience. Ann Thorac Surg 1990;50:367-73.

15. David TE, Bos J, Rakowski H. Mitral valve repair by replacement of chordae tendineae with polytetrafluoroethylene sutures. J Thorac Cardiovasc Surg 1991;101:495-501.

16. David TE, Armstrong S, Sun Z, Daniel L. Late results of mitral valve repair for mitral regurgitation due to degenerative disease. Ann Thorac Surg 1993;56:7-14.

17. Kanemoto I, Taguchi D, Mihara K, et al. Long-term survival of two dogs after mitral valve plasty. Vet Sci Develop 2016;7:6335. 